\title{
X-RAY DIFFRACTION AND SEM ANALYSIS OF WASTE SULFUR MODIFICATION FOR USE IN CONCRETES
}

\author{
Nataša G. Đorđević ${ }^{1}$, Milica M. Vlahović ${ }^{2}$, Sanja P. Martinović ${ }^{2}$, Mladen D. \\ Bugarčić ${ }^{1}$, Slavica R. Mihajlović ${ }^{1}$,
}

Received: March 6, 2021

Accepted: May 16, 2021

\begin{abstract}
Secondary sulfur obtained as a by-product in the oil refining process is a major problem as an environmental pollutant. One of the possibilities of environmental protection is the use of sulfur obtained in this way as a component of sulfur concrete. Mixing of sulfur with suitable additives can provide longer working lifetime of sulfur concrete, as well as maintenance of the former physical, chemical, and mechanical properties of concrete. Such mixtures are usually called modified sulfur or sulfur cement. Secondary sulfur produced in the oil refining process by the Klaus process (approval of crude oil) cannot be used in this form. In order to be ready for the use of sulfur concrete and asphalt, it is necessary to modify elemental sulfur from cyclic to chain form, obtaining of modified sulfur whose application is as a binding agent in a concrete instead of portland cement is described in this paper. Influence of dicyclopentadien, an organic additive, on sulfur modification has been studied in this research. Microstructure and mineral analysis of modified and unmodified sulfur cement binding are performed using polarized and scanning electron microscopes and X-ray diffraction spectrometer.
\end{abstract}

Keywords: modified sulfur; dicyclopentadiene; binding agent

\section{INTRODUCTION}

In recent years, there is enormous increase in the production of sulfur in whole world. It is a huge problem to consume the large quantity of sulfur produced. Many researchers have dealt with the problem of the use of elemental (secondary) sulfur (Mohammed, and Poornima, 2018). This situation has led to use the sulfur as a low-cost construction material for producing sulfur concrete and sulfur infiltrated concrete. For instance, the current sulfur production in Kuwait is almost 1 million tons per year, and almost 50\% of that amount is used to obtain sulfuric acid and its products (Otaibi et al. 2019). The constant increase in the production of secondary sulfur indicates the need for its

\footnotetext{
${ }^{1}$ Institute for Technology of Nuclear and Other Mineral Raw Materials, 86 Franchet d'Esperey Blvd., Belgrade, Serbia

${ }^{2}$ University of Belgrade, Institute of Chemistry, Technology and Metallurgy, 12 Njegoševa St, Belgrade, Serbia

E-mails: n.djordjevic@itnms.ac.rs; m.vlahovic@ihtm.bg.ac.rs; s.martinovic@ihtm.bg.ac.rs m.bugarcic@itnms.ac.rs; s.mihajlovic@itnms.ac.rs.
} 
application in various fields. Many research projects have been carried out in order to find possibilities for secondary sulfur to be modified and applied. The field of industry where modified sulfur has found the greatest application is construction, in civil engineering, as a part of sulfur concrete mixture and sulfur asphalt.

Sulfur concrete uses sulfur as the binding agent for aggregate. Thereby, modified sulfur replaces the cement and water components of a regular portland cement concrete mix. Sulfur concrete may prove to be a cost-effective substitute for portland cement concrete in certain applications. Thanks to its properties, it is not only cheaper as a material, but also shows many other properties that concrete based on portland cement does not have. Many properties of modified sulfur concrete are: high strength, fatigue resistance, excellent corrosion acids and salts resistance, it is very stable material, without changing its chemical properties and it is relatively safe to use (Vlahović et al. 2011; Yoon, 2006; Xiao et al. 2005; Sheen et al. 2004). In addition to all these facts, many researchers have explored the possibility of sulfur concrete's commercial success. The success of using sulfur also depend upon solving the problem for how to develop the necessary sulfur infrastructure (supply and transport), so the price can be competitive with the price of portland cement (Kim et al. 2010; Cha et al. 2011; Vlahović et al. 2013; Walraven, 1998).

The materials based on sulfur concrete, which has relatively simple composition, have many specialized applications in the construction industry. Due to its properties, this material can be used primarily in areas where conventional materials like Portland cement concrete has failed, such as in acidic and saline chemical environments (Nielsen and Glavind 2007; Mohamed and El Gamal 2010; Vlahović et al. 2011; Vlahović et al. 2013; Eckert, 2003).

Procedure of sulfur concrete preparation is based on warming up of sulfur to the temperature of $119{ }^{\circ} \mathrm{C}$ and subsequent mixing of obtained melted sulfur into the aggregate (classic construction mixture). Crystallization of sulfur in the form stable on higher temperature is reached by fast cooling of mixture (melted sulfur and aggregate). However, sulfur transformation and change of crystal modification are happening in time, and result of this process is losing of former properties of sulfur concrete. This phenomenon, which considerably shortens working lifetime of sulfur concrete and therefore limits its application, directed further researches towards finding way for stopping or complete prevention of changing sulfur crystal modification in time. Modified sulfur means sulfur in polymerized form obtained by adding chemical additives-modifiers to elemental sulfur and many researches has been directed in that field.

One of directions in our research was to utilize not only some of the secondary sulfur physical and chemical properties, that are chemical passivity above all, high resistance to aggressive agents (first of all acids) and outstanding hydrophobicity, but also to provide stability of sulfur crystal modification after fast cooling and long holding on ambient temperature. Applications of various additives for sulfur modification have been 
studied by many researchers with the aim to obtain specific form of sulfur crystallization on the occasion of cooling and solidification.

Sulfur obtained from the process of oil refining has orthorhombic modification $(\mathrm{S} \alpha)$, a stable form of sulfur at room temperature. Its color is yellow and its solubility in alcohol and ether is low, while in carbondisulphide is extremely high. Unmodified sulfur treated at temperature above $180^{\circ} \mathrm{C}$ has a form of polymer sulfur -(-S-) n- which, during cooling from liquid crystalizes as monoclinic sulfur $(\mathrm{S} \beta)$ with needle structure at $119^{\circ} \mathrm{C}$ followed by volume decreasing of $7 \%$. Further cooling bellow $95.4^{\circ} \mathrm{C}, \mathrm{S} \beta$ form begins to transform into orthorhombic sulfur $(\mathrm{S} \alpha)$. As $\mathrm{S} \alpha$ form is much denser than $\mathrm{S} \beta$ form, great stress that can provoke earlier fractures will be induced in the material (ACI, 1998).

Previous researches and comparing of unmodified and modified sulfur cement were based on XRD analysis. They show that majority of XRD diagrams indicate presence of orthorhombic sulfur modification $(\mathrm{S} \alpha)$, with very narrow and pronounced peaks, but in some cases in which sulfur is modified by high percentage of polymer modifier, 20-25 $\%$, XRD diagrams shown small amount of monoclinic $\mathrm{S} \beta$ or peaks of $\mathrm{S} \alpha$ were not distinctive. That points to the presence of monocrystaline sulfur. Modification should provide as higher level of sulfur polymerization as possible, i.e., structure with as longer sulfur chains as possible. Namely, additives are materials that can hang on the end of the formed sulfur chains and in that way prevent forming rings during further cooling. Accordingly, to this, influence of dicyclopentadien, an organic additive, on sulfur modification has been studied in this research (ACI MCP604, 2004; Blight et al. 1978).

\section{MATERIALS AND METHODS}

Raw materials for modified sulfur cement obtaining are: waste sulfur from the Claus process of oil refining in Oil Refinery NIS Pančevo ( $99.9 \%$ purity) and modifier, DCPD, an organic polymer compound. The procedure was based on sulfur heating, whereby melted sulfur was preparing, then mixing into modifier and their homogenization. An adapted unit with thermostat for asphalt obtaining was used. Temperature of melted sulfur should not exceed $141^{\circ} \mathrm{C}$ in order to avoid sulfur emission into atmosphere.

The melt was prepared: $80 \%$ waste sulfur and $20 \%$ dicyclopentadiene. Samples of waste sulfur heated up to $140{ }^{\circ} \mathrm{C}$. Then, appropriate amount of dicyclopenthadien was mixed into the melt and mixing continued for $30 \mathrm{~min}$, at $120^{\circ} \mathrm{C}$. After homogenization, the melt was spilt in thin film for the purpose of achieving fast cooling (cooling duration is $5 \mathrm{~min}$ ). Fast cooling is necessary in order to prevent dicyclopenthadien capturing in ring of sulfur and facilitate sulfur polymer chains formation.

Sulfur cement and unmodified sulfur, obtained in a same way- by melting of waste sulfur, were subjected to X-ray diffraction and microstructural analysis. 
X-ray diffraction analyses for samples of $80 \%$ sulfur and $20 \%$ dicyclopentadiene was used for determination and tracking of phase composition of samples. The samples were analyzed by X-ray diffractometer, type Philips, model PW-1710.

Mineral analyses were done by scanning electron microscope, type "Joel" with microsonde (magnification of 1000, 2000, 5000, 30.000 and 50.000 X).

\section{RESULTS AND DISCUSSION}

Figure 1 shows the XRD analyses of sulfur, unmodified and modified with $20 \%$ of DCPD. The difference which is presence of orthorhombic sulfur $(\mathrm{S} \alpha)$, the only stable form of sulfur at room temperature. However, in some samples, small quantity of monoclinic sulfur was also detected.

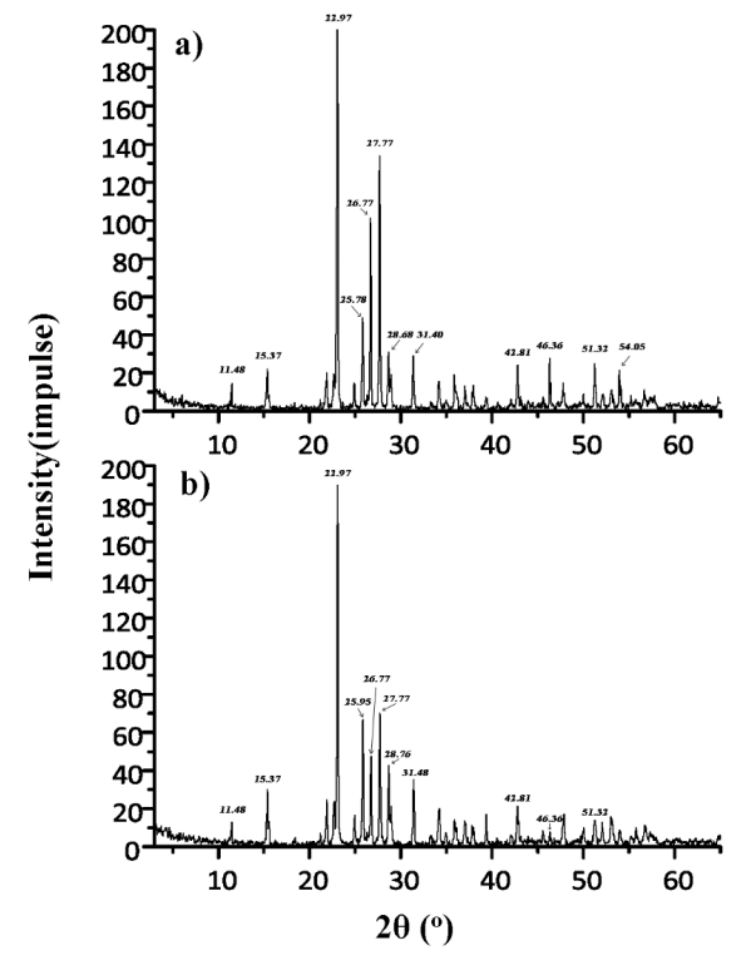

Figure 1 XRD analyses: a) modified sulfur cement (20\% DCPD), b) unmodified sulfur

The distance between the crystal planes increased in the modified relative to the unmodified sulfur (values from 25.95 degrees to 25.78 and from 28.76 to 28.68 as well as from 31.48 to 31.40$)$.

Existence of morphological changes is observed by SEM microscopy. Insignificant morphological changes point out to the fact that mainly chemical changes of material 
occur, with slight structural changes. This is in correspondence with XRD analyses which proved only the existence of stable forms of sulfur.

According to the obtained results it can be concluded that modified sulfur cement has more compact and homogeneous structure, higher viscosity, better consistency meaning lower porosity and higher degree of packing. Macro sulfur crystals are not present in the modified sulfur structure. The existence of long sulfur chains is noticed. This can be explained by the fact that sulfur itself has great tendency to polymerize and this effect is intensified by modification. On the other hand, some common crystallization features were observed in the areas where sulfur shrinkage left voids.

SEM of unmodified sulfur cement is given in Figure 2. 

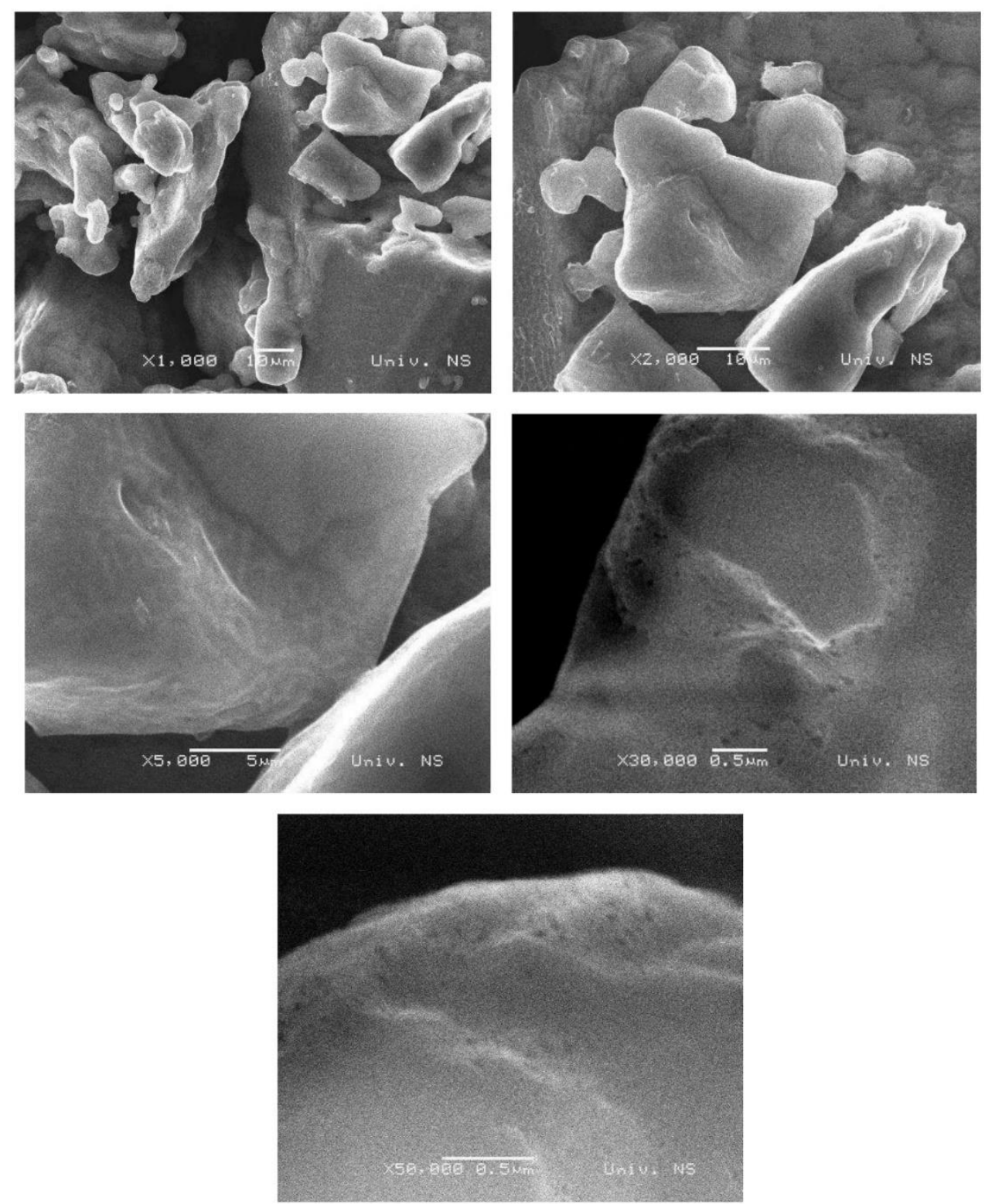

Figure 2 SEM of unmodified sulfur

SEM of modified sulfur cement (with $20 \%$ dicyclopentadiene) is presented in Figure 3. 

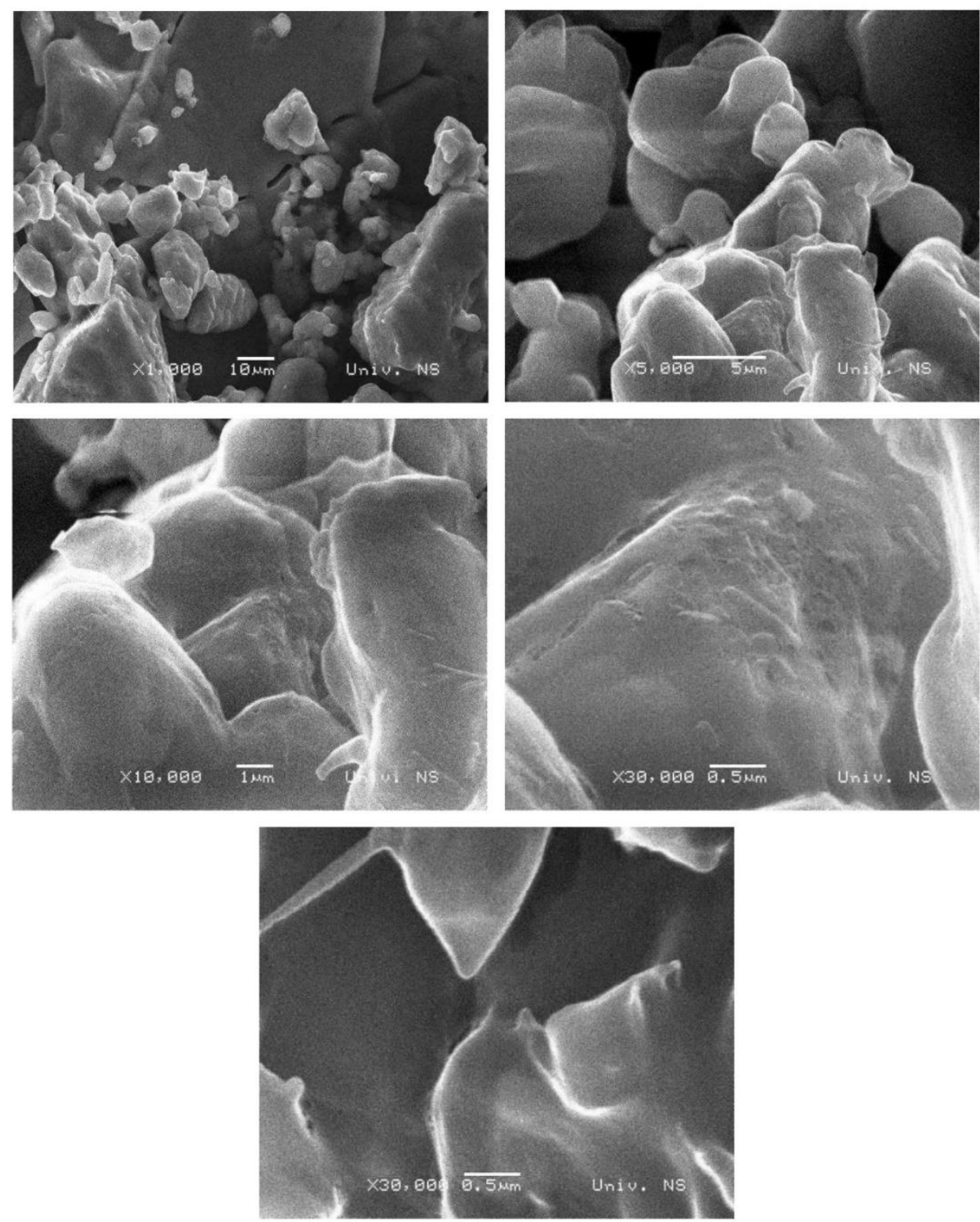

Figure 3 SEM of modified sulfur cement with $20 \%$ DCPD

Those investigations show that SEM is the most adequate method of analysis for comparison of modified and unmodified structures since SEM offers neat and distinctive images with distinguishable features.

Figure 2 and 3 shows the SEM analysis of unmodified and modified sulfur with $20 \%$ modifier. The structure of pure sulfur consists of dense orthorhombic crystals of alpha 
form ( $\mathrm{S} \alpha$ ), Figure 2, while the modified sulfur consists of plate monoclinic crystals of beta form $(S \beta)$, partially polymerized in zigzag chains, Figure 3. In this way, it was confirmed that sulfur modification was achieved.

\section{CONCLUSION}

- Higher level of polymerization was provided by sulfur modification. Used organic polymer, dicyclopentadien in amount of $20 \%$ was suitable to form sulfur chains and prevent forming rings during cooling.

- $\quad$ Orthorhombic sulfur $(\mathrm{S} \alpha)$ was detected by XRD analyses.

- Morphological changes of sulfur were proved by SEM microscopy.

- $\quad$ Modified sulfur shows satisfied properties for usage in concretes.

- Waste sulfur modification and its application for concretes and mortars preparation enables solving serious environmental problem.

\section{ACKNOWLEDGEMENTS}

This work was financially supported by the Ministry of Education, Science and Technological Development of the Republic of Serbia (Grant Nos. 451-03-9/202114/200023 and 451-03-9/2021-14/200026).

\section{REFERENCES}

MOHAMMED, S. and POORNIMA, V. (2018) Strength and durability study of sulfur concrete with replaced fine aggregate. Materials today, 5 (11/3), pp. 23888-23897

OTAIBI, S. et al. (2019) Potential for producing concrete blocks using sulfur polymeric concrete in Kuwait. Journal of King Saud University - Engineering Sciences, 31(4) pp. 327-333

VLAHOVIĆ, M. M. et al. (2011) Durability of sulfur concrete in various aggressive environments. Construction and Building Materials, 25, pp. 3926-3934

YOON, J. H. (2006) An experimental study on the durability of sulfur concrete. Journal of the Architectural Institute of Korea Structure \& Construction, 22(6), pp. 95-102.

XIAO, J. et al. (2005) Mechanical properties of recycled aggregate concrete under uniaxial loading. Cement \& Concrete Composites; 35, pp. 1187-1194

SHEEN, D. H. et al. (2004). Preparation of modified sulfur concrete pipe using centrifugal force. In: Proceeding of 2004 Annual Conference, KSCE pp. 513-520 
KIM, J.C. et al. (2010) The fundamental study of modified sulfur concrete. Korean Recycled Construction Resource Institute. 2010; Spring conference session 3-3: pp. 7982

CHA, S. W. et al. (2011) Manufacture of modified sulfur polymer binder and properties of sulfur concrete. Korea Concrete Institute, 23(6) pp.40-42

VLAHOVIĆ, M. et al. (2013) Quantitative evaluation of sulfur-polymer matrix composite quality Composites Part B. Engineering, 44 (1) pp. 458-466

WALRAVEN, J.C. (1998) The development of self-compacting concrete in the Netherlands. International Workshop on Self-compacting Concrete. Kochi, Japan, pp. $87-96$.

NIELSEN, C.V., and GLAVIND, M. (2007) Danish experience with a decade of green concrete. J. Adv. Concr. Technol. 5 (1), pp. 3-12.

MOHAMED, A.M.O. and EL GAMAL, M.M. (2010) Sulfur concrete for the construction industry, a sustainable development approach. J. Ross Publishing

VLAHOVIĆ, M. et al. (2011) Durability of sulfur concrete in various aggressive environments. Constr. Build. Mat. 25 (10), pp. 3926-3934.

VLAHOVIĆ, M. et al. (2013) Quantitative evaluation of sulfur-polymer matrix composite quality. Compos. Part B: eng. 44 (1), pp. 458-466.

ECKERT, B. (2003) Molecular Spectra of Sulfur Molecules and Solid Sulfur Allotropes, pp. 31-98. In: Steudel, Ralf. (Ed.) Elemental Sulfur and Sulfur-Rich Compounds II, Springer

ACI (1998), "Guide for mixing and placing sulfur in construction", Report 548.2R-93 American concrete Institute

ACI MCP604 (2004) Manual of Concrete Practice Part 6, American Concrete Institute

BLIGHT, L. et al. (1978) Preparation and properties of modified sulfur systems, New Uses of Sulfur-II, Advances in Chemistry series, American Chemical Soc., pp.165 